\title{
Pore structure and mechanical properties of cement-lime mortars
}

M. Arandigoyen, J.I. Alvarez *

Departamento de Química, University of Navarra, 31080 Pamplona, Spain

$\mathbf{N}^{\circ}$ of pages: 23

$\mathbf{N}^{0}$ of tables: 3

$\mathbf{N}^{\circ}$ of figures: 8

Keywords: D, Blended cement; E, mortar; C, mechanical properties; C, elastic moduli;

B, pore size distribution

Please, send all correspondence to:

Dr. José I. Alvarez Galindo

Dpto. de Química

Fac. de Ciencias

Universidad de Navarra

$\mathrm{C} /$ Irunlarrea $\mathrm{s} / \mathrm{n}$

31080 Pamplona (Navarra)

Spain

Phone: 34948425600

Fax: 34948425740

E-mail: jalvarez@unav.es 


\title{
Pore structure and mechanical properties of cement-lime mortars
}

\begin{abstract}
Studies focusing on materials used in Cultural Heritage conservation projects are becoming increasingly important. In this paper, pore structure and mechanical properties of lime-cement mortars are evaluated in order to analyze their potential use, because this kind of mortar could reduce the disadvantages presented by both limebased mortars and cement-based mortars. The microstructure of these blended mortars is studied taking into account porosity, pore size distribution and surface fractal dimension. Compressive and flexural strengths are discussed as a function of several parameters: curing time, binder composition and $\mathrm{B} / \mathrm{Ag}$ (Binder/aggregate) ratio. The mechanical strength versus the deformation of the material is also evaluated, by analysis of Young's modulus, as well as the elastic and plastic zones. Unlike cement-based mortars, blended mortars with a high percentage of lime present a large plastic zone, which could be useful in the service-life of these mortars as a result of their ability to absorb strains caused by wall movements.
\end{abstract}

Keywords: D, Blended cement; E, mortar; C, mechanical properties; C, elastic moduli; $\mathrm{B}$, pore size distribution 


\section{Introduction}

For several centuries lime-based mortars were used as binding materials in monuments. Aerial lime was commonly used, and the final characteristics of the mortars were strongly dependent on the civilization. As a consequence, now a broad variety of mortars can be found in historical buildings. Nowadays, these traditional mortars have been replaced with cement mortars [1]. Several characteristics have been attributed to lime-based mortars: (i) slow setting that hinders and delays restoration work; (ii) lime mortars present lower strengths than cement mortars, and take longer to reach them. Together with that, there is a lack of rigorous studies about these material.

Cement-based mortars have therefore displaced lime-based mortars because of their faster setting, higher mechanical strength and advanced industrial development and affordable cost. However, in spite of their wide use in Civil Engineering, cement-based mortars have been found to present major disadvantages as repair mortars for Cultural Heritage restoration [2]: (i) they present a serious incompatibility with old stones; (ii) they have a high salt content, which can damage the stone by crystallization and/or hydration cycles; (iii) they have been found to have low flexibility, in contrast with lime-based mortars, which hinders the accommodation of movement resulting from creep or thermal effects $[3,4]$. In recent times, restoration interventions carried out using cement mortars have caused significant failures and acceleration of damage to the monument, which leads to the conclusion that cement-based mortars are unsuitable, as they are incompatible with historic buildings [1].

Study of different binding materials has been carried out in response to the reported objections to both lime and cement mortars. These materials should have the following characteristics: (i) chemical compatibility between the repair mortar and the old 
materials (stone or brick and their bedding mortar); (ii) physical compatibility, with special reference to the processes of solubility and water transport; (iii) structural and mechanical compatibility with ancient materials, stones and mortars. One previous study states specifically that a repointing mortar should be considerably weaker than the stone, and should deform significantly before failure [3].

The use of some blended mortars could be interesting in this sense, because lime mortars with a certain amount of cement added might behave like hydraulic mortars, which are characterized by higher strengths than lime mortars (but no as high as cement mortars), as well as a faster setting time, which improves their application [5-7]. In some countries, such as Spain, the availability of natural commercial hydraulic lime is very low, so it may be useful to know whether cement-lime mortars have similar behaviour to hydraulic-lime mortars, since suitable cement-lime mixtures are easier to prepare and more widely available. Previous papers have reported some aspects of these materials such as: the viscosity of lime-cement paste [5], the effect of aggregate composition in pozzolan repair mortars [8], and the effect of silica fume addition [9]. Our research group has studied the pore structure and capillary porosity [10] and the variation of microstructure during the carbonation of lime [11] in blended pastes.

During the setting and hardening processes of a mortar, various physical and chemical phenomena take place as a function of the binder composition:

i) In lime-based mortars the drying of the kneading water takes place, together with a certain degree of shrinkage [2]. The carbonation process starts when the water content of the mortar does not hinder the diffusion of the air through the material [12].

ii) In cement-based mortars the setting is a consequence of the hydration of the calcium silicates, which starts quickly owing to the hydration of the $\mathrm{C}_{3} \mathrm{~S}$ and 
continues more slowly because of the hydration of the $\mathrm{C}_{2} \mathrm{~S}$. The hydration of both compounds gives strength to the mortar [13]. The carbonation process also takes place slowly. The carbonation of cementitious materials is a reaction of the basic compounds of hydrated cement (essentially $\mathrm{Ca}(\mathrm{OH})_{2}$ and $\mathrm{CSH}$ ) with carbonic acid. This phenomenon has been studied at length [14].

However, from the review of the literature, the absence of a systematic study of the mechanical properties of these blended mortars is noticeable. This kind of study should analyze the influence of several important factors, such as the dosage of cement or the $\mathrm{B} / \mathrm{Ag}$ (binder/aggregate) ratio. This paper aims to add to the experimental data on the mechanical behavior of lime-cement mortars in the full range of compositions (from $100 \%$ cement mortars up till $100 \%$ lime mortars). The influence of the $\mathrm{B} / \mathrm{Ag}$ ratio is discussed as well as the modulus of elasticity. Pore structure (and surface fractal dimension, as an indicator of it) is also evaluated, because it is responsible for capillary absorption and moisture transport, phenomena which are related to the durability, degradation and service life of building materials [15-17]. The results obtained have been compared with the results for cement-lime pastes [10,11], which allows us to analyze the changes due to the addition of the aggregate. 


\section{Experimental study}

\subsection{Paste preparation}

189 prismatic specimens of 40x40x160 mm were prepared by mixing three components: a hydrated commercial lime powder (Ecobat $\left.{ }^{\circledR}\right)$ (supplied by Calinsa S.A, Navarra, of the class CL90 according to the Spanish standard [18]), Portland cement CEM II-A/L 32.5 (according to the Spanish standard [19]), and a commercial calcite aggregate made up of crushed stones. Seven cement/lime ratios (by volume, including the full range of cement-lime compositions) were combined with three $\mathrm{B} / \mathrm{Ag}$ ratios (by volume) to produce twenty-one different mortars (Table 1). The three B/Ag ratios for each binder composition - (1:2) to (1:4) - were chosen among the commonest dosages reported in the literature [2].

Table 2 shows the chemical analyses of the lime $\left(\right.$ Ecobat $\left.^{\circledR}\right)$, the cement (CEM II-A/L 32.5) and the aggregate. XRD and TG-DTA analyses were carried out with the aim of studying the mineralogical composition of lime and cement. The XRD (Fig. 1) and TGDTA analyses of the lime show two mineralogical phases: portlandite $(87 \%)$ and calcite (10\%), with a $3 \%$ of free water. Magnesium compounds $\left(\mathrm{MgO}, \mathrm{Mg}(\mathrm{OH})_{2}\right.$, dolomite), which were shown to present slower carbonation rates, were not found. The XRD results for the cement (Fig. 2) show the well-known anhydrous phases of a clinker (calcium silicates and aluminates). Figure 3 shows the cumulative particle size distribution of the aggregate. The main particle size ranges from 0.1 to $2 \mathrm{~mm}$, with $20 \%$ smaller than $0.1 \mathrm{~mm}$.

During the preparation of the mortars, before the addition of the aggregate, lime and cement were intimately mixed. Then a specific amount of water was added with the aim of obtaining a similar consistency and workability (measured by the flow table test) [20] for all the fresh mortars. Pastes were blended for 5 minutes in a Proeti ETI 26.0072 
mixer, molded in prismatic casts and demolded 3 days later. The specimens were cured in a vertical position in a laboratory environment $\left(\mathrm{RH} 60 \pm 10 \%\right.$ and $\left.20 \pm 5^{\circ} \mathrm{C}\right)$. The surrounding $\mathrm{CO}_{2}$ in the room was estimated to be the standard atmospheric concentration $(0.033 \pm 0.001 \%$ by volume $)$.

Tests and analyses were conducted using the techniques described below after curing times of 3, 7, 28, 91 and 365 days: one specimen was tested at 3 days after curing, two after 7 days, three after 28 days, two after 91 days and one after 365 days. The reported results are an average value of the similar specimens, and the coefficients of variation are below 5\% in compressive strength results.

\subsection{Analytical methodology}

\subsubsection{XRD analysis}

The mineralogical phases of the mortars were determined by means of X-ray diffraction (XRD) using a Brucker D8 Advance diffractometer, according to the diffraction powder method, with a $\mathrm{CuK}_{\alpha 1}$ radiation and $0.022 \theta$ increment and $1 \mathrm{~s} \cdot \mathrm{step}^{-1}$, sweep from 10 to $80^{\circ} 2 \theta$. The results were compared with the ICDD database.

\subsubsection{Thermal analysis}

Differential thermal and thermogravimetric analysis (DTA-TG) were conducted using a simultaneous TGA-sDTA 851 Mettler Toledo thermoanalyser, with alumina crucibles, fitted with pierced lids, at $20^{\circ} \mathrm{C} \cdot \mathrm{min}^{-1}$ heating rate, under static air atmosphere.

\subsubsection{Pore structure}

The pore structure was evaluated in two ways: 
2.2.3.1. Open porosity measurement: the total porosity is expressed as $\mathrm{P}$, in percent, and it was determined according to the water saturation test [21] with a hydrostatic balance.

2.2.3.2. Pore size distribution was evaluated using the mercury intrusion porosimetry technique with a Micrometrics 9320 Poresizer mercury porosimeter, which automatically registers pressure, pore diameter, intrusion volume and pore surface area.

\subsubsection{Mechanical properties}

The mechanical properties were evaluated in two ways:

2.2.4.1. The three-point flexural tests were carried out using a Frank/Controls 81565 compression machine at low rates of loading ( $4 \mathrm{~mm} / \mathrm{min})$. Flexural strength determination was performed on the Ibertest IB 32-112V01.

2.2.4.2. Compressive strength tests were conducted on the two fragments of each specimen resulting from the preceding flexural test. Compressive strength determination was carried out on a Proeti ETI 26.0052, with a loading rate of 4 $\mathrm{mm} / \mathrm{min}$. The reported results are the average value of the identical specimens. 


\section{Results}

\subsection{Pore Structure}

\subsubsection{Porosity}

Table 3 shows that the porosity in these mortars can be considered constant. Only slight differences of porosity between the different binder compositions can be perceived (lime:cement ratios). These results are somewhat surprising, because previous studies have reported striking differences in the porosity of lime-cement pastes, so that the higher the percentage of lime in the paste, the higher the porosity $[10,11]$. In these previous experiments porosity was found to range from 50 to $65 \%$ in lime pastes (as a function of the W/B (water/binder) ratio) [22], whereas its value was around $30 \%$ in cement pastes [10]. Contrary to expectation, in the current paper, the analysis of limecement mortars shows that porosity remained almost invariable (ranging from 20 to $23 \%)$.

This slight increase in porosity was noticed when the quantity of binder increased (from $\mathrm{B} / \mathrm{Ag}$ ratio $1: 4$ to $1: 2$ ). This increase was proven to be independent of the lime:cement ratio. Other research also registered this small variation in lime-based mortars $[2,7]$. Nevertheless, these previous authors reported a dramatic increase in porosity for the highest $\mathrm{B} / \mathrm{Ag}$ ratios $(1: 1,2: 1$ or $4: 1)$.

\subsubsection{Pore size distribution}

Figure 4 shows the cumulative pore size distribution (\%) of the mortars with different $\mathrm{B} / \mathrm{Ag}$ ratio: $1: 2,1: 3$ and 1:4. The intrusion volume registered includes both the pores and the microcracks created as a result of the internal strains (which could take place, for example, during the setting of the material) [23]. 
Using MIP, previous research on the microstructure of both lime pastes and cementlime pastes has concluded that all the pore diameters are smaller than $1 \mu \mathrm{m}[10,22]$.

Nevertheless, the pore size distributions of the mortars in the current study present a large proportion of pores greater than $1 \mu \mathrm{m}$. As can be seen from the data in Figure 4, this fact must be highlighted in lime-rich mortars ( $>50 \%$ of lime).

\subsubsection{Surface fractal dimension}

In a previous paper [24], pore fractal objects were defined as dense objects within which there exists a distribution of pores with a fractal structure. Fractal geometry is used to describe chaotic systems which are characterized by their invariability at any scale used to examine them; any part of the system looks the same as the whole (self-similarity) [25]. The system is determined by fractal dimension value, which is defined as an intermediate dimension between the Euclidean dimensions (point 0, line 1, plane 2 and volume 3) as a consequence of the complexity of the system [26].

This value $\left(D_{S}\right)$ can contribute to a description of the heterogeneity and complexity of the pore system. Perez Bernal et al. explained and compared several methods to calculate this parameter [25]. In the present paper the Zhang and Li model [27] (derived from thermodynamic considerations and the analysis of dimensions) has been applied to the MIP collected data (Eq. 1). In order to obtain the value of $\mathrm{D}_{\mathrm{S}}$, the $\mathrm{Q}_{\mathrm{n}}$ term was plotted versus the $W_{n}$ term, and several $D$ values were estimated until they fitted a straight line (with a slope value of 1 ). The $\mathrm{D}$ value obtained is the surface fractal dimension.

$$
Q_{n}=-\sum_{i=1}^{n} \overline{P_{i}} \Delta V_{i} \quad \propto \quad r_{n}^{2-D} V_{n}^{D / 3}=W_{n}
$$


where, $\mathrm{P}$ is the applied pressure, $\mathrm{V}$ is the intrusion volume of mercury, $\mathrm{r}$ is the pore radius, $\mathrm{D}$ is the surface fractal dimension, $\mathrm{Q}_{\mathrm{n}}$ is the short expression of $-\sum_{i=1}^{n} \bar{P}_{i} \Delta V_{i}$ and $\mathrm{W}_{\mathrm{n}}$ is the short expression of $r_{n}^{2-D} V_{n}^{D / 3}$.

The good correlation coefficients obtained $(\sim 0.99)$ show the good adjustment of these materials to the Zhang and Li's model. In accordance with Pfeifer and Obert [28], the range of pore diameters used to calculate the fractal dimension must include at least one order of magnitude with the purpose of accepting the experimental value of the fractal dimension. In the present study this model has been applied to the full pore range obtained by MIP, which includes around four orders of magnitude.

Figure 5 presents the $D_{S}$ versus the percentage of lime in the binder for each one of the mortars. In the three series with different $\mathrm{B} / \mathrm{Ag}$ ratio, it can be seen that the higher the percentage of cement in the binder, the higher the $\mathrm{D}_{\mathrm{S}}$. An identical behavior can be seen in a previous study on lime-cement pastes [10]. However, in mortars the variation in the interval is smaller than in pastes.

The values of the slope of the straight line that links the values of $\mathrm{D}_{\mathrm{S}}$ are very similar for each of the three series with different $\mathrm{B} / \mathrm{Ag}$. The $\mathrm{D}_{\mathrm{S}}$ variation is shown to be independent of the $\mathrm{B} / \mathrm{Ag}$ ratio throughout the same series (with the same $\mathrm{B} / \mathrm{Ag}$ ratio). Nevertheless, the value of the $\mathrm{D}_{\mathrm{S}}$ changes clearly as a function of the $\mathrm{B} / \mathrm{Ag}$ ratio. For instance, in mortars with the same binder composition, the smaller value of $\mathrm{D}_{\mathrm{S}}$ matches the $1: 3 \mathrm{~B} / \mathrm{Ag}$ ratio; the intermediate one matches the 1:4 ratio; and the highest one matches the $1: 2$ ratio. 


\subsection{Mechanical properties}

\subsubsection{Influence of the curing time}

We must emphasize that the curing process was conducted in laboratory conditions (HR $60 \pm 10 \%$ and $20 \pm 5^{\circ} \mathrm{C}$ ), which are not the most suitable for the hydration of calcium silicates. Figure 6 shows the values of the compressive and flexural strength, versus the curing time. From the data, two different evolutions of the mechanical properties can be clearly observed:

i) In mortars with a lime-rich binder, a continuous increase in mechanical strengths occurs (cement-lime 0-1 and 1-8).

ii) In mortars with a cement-rich binder, an increase in strength can be observed at the beginning of the curing days (registered until the $7^{\text {th }}$ day). Nevertheless, next a drop in strength is observed before a new increase registered at the $365^{\text {th }}$ day. In the compressive strength, the decrease is confirmed at the $91^{\text {st }}$ day (except for mortars 1-0-3 and 1-0-4, in which the strength decreases from the $28^{\text {th }}$ day). However, in the flexural strength the decrease generally begins at the $28^{\text {th }}$ day. The reduction in strength shifts towards earlier curing ages when the cement content increases.

\subsubsection{Influence of the binder composition}

As expected, the binder composition has a significant influence on the mechanical properties of the mortar. The following facts have been established in both the compressive and the flexural strengths:

i) The lime-rich mortars show small variations of the mechanical strength when the binder composition changes. For example, the mechanical 
strengths present very slight changes if the cement percentage ranges from 0 to $40 \%$ (cement-lime ratios of $0-1,1-8$ and $1-4$ ).

ii) The cement-rich mortars show a wide variation in their mechanical properties: an outstanding fall in their mechanical strengths has been established when a certain amount of lime is added to the cement.

It can thus be concluded that if certain amount of cement is added $(0-40 \%)$, the mechanical strength of lime mortars increases slightly, whereas in cement mortars, the mechanical strength diminishes considerably if a small amount of lime is added: for instance, the addition of $25 \%$ of lime gives rise to $50 \%$ loss of strength.

\subsubsection{Influence of the $\mathrm{B} / \mathrm{Ag}$ ratio}

It is well-known that cement mortars increase their mechanical strengths if the amount of binder in the mortar increases [23]. The same behavior has been reported for limebased mortars [2,7]. Therefore, analogous behavior might be expected for lime-cement mortars. The data in Fig. 6 confirm the strength increase over the curing time.

The $\mathrm{B} / \mathrm{Ag}$ ratio has a strong influence on the strength values: $40 \%$ of the rise can be observed from (1:4) to (1:3), and from (1:3) to (1:2). These variations are outstanding for rich-in-cement mortars.

\subsubsection{Young's modulus}

Figure 7 shows the compressive strength versus the deformation for (1:2) B/Ag ratio mortars.

As can be noticed in Fig. 7, the limit of strength (beyond which breakage takes place) fits in with a straight line for the majority of the mortars belonging to the same $\mathrm{B} / \mathrm{Ag}$ ratio series. Only the two richest-in-lime mortars do not fit in with this straight line 
owing to the presence of a noticeable plastic zone before breakage. These plastic zones are characterized by a smaller slope: in these areas, if the load disappeared the material would not recover its initial characteristics, but would suffer a permanent deformation. From the results, it can be established that the higher the amount of cement, the lower the plastic zone. In addition, in mortars with over 50\% cement, the plastic zone is actually lost, and the mortars go through the elastic zone up until breakage of the material.

This plastic zone is not observed during the flexural strength tests, in which all mortars just break after the elastic zone.

\section{Discussion}

In mortars, it must be considered:

i) the pores of the aggregate, which depend on the nature of the aggregate;

ii) the pores of the binder, which also depend on the chemical and mineralogical composition of the binder and the W/B ratio [10,22,29]. It has been established that the amount of kneading water does not modify the complexity of the pore system, at least in lime pastes [22], but does change the porosity;

Previous works have demonstrated that the binder is the main factor responsible for the porosity in the mortar, not including the most porous aggregates [2,7]. Therefore, the W/B ratio should play an important role in the porosity. Actually, the amount of kneading water has been reported as the main determining factor of the porosity [29].

It can be stated that the higher the $\mathrm{B} / \mathrm{Ag}$ ratio, the smaller the $\mathrm{W} / \mathrm{B}$ ratio. This phenomenon can be attributed to the fact that the mortars were prepared in order to achieve similar consistency (workability) for all the fresh pastes. Workability is extremely important in order to apply the mortar on the building site. In mortars with 
small amounts of binder, the reduction in porosity due to the smaller percentage of binder would achieve an equilibrium with an increase in porosity owing to the evaporation of a larger amount of kneading water. This dependence of the porosity on the $\mathrm{B} / \mathrm{Ag}$ (in line with $\mathrm{W} / \mathrm{B}$ ) ratio can be confirmed by the fact that the values for porosity are practically constant with changing lime:cement ratios (Table 3). This behavior is clearly different from the behavior of the pastes, so it can indicate that it has its origin in the addition of the aggregate.

However, two facts about pore size distribution remain unexplained at this point:

i) As can be seen from the data in Figure 4, there is a proportion of different pores $>1 \mu \mathrm{m}$ which did not appear in pastes [10]. When the amount of aggregate in the mortar increases, the percentage of pores higher than $1 \mu \mathrm{m}$ increases slightly.

ii) The MIP results (Fig. 4) show that when the amount of aggregate increases, the pore size distribution shifts towards smaller diameters of pore.

As a possibility, we suggest that pores $>1 \mu \mathrm{m}$ could be attributed to the ITZ (interfacial transition zone), formed by pores that are partly bordered by the aggregate and by the binder. These ITZ pores depend on the nature of the binder (also affected by the W/B ratio) and aggregate. In cement mortars, it has been stated that the ITZ is characterized by its high porosity, smaller degree of hydration of calcium silicates and greater percentage of portlandite than in the rest of the mortar [30]. The origin of pores $<1 \mu \mathrm{m}$ turn out to be more difficult to explain: the smaller porosity of the aggregate and/or the occurrence of ITZ could have some influence on these results. However, further BSE studies should be carried out in order to characterise the pore structure of this ITZ and confirm these hypothesis. 
Concerning the Ds values, the smaller variation found in the interval compared with those observed in the pastes [10] can be explained because the change is mainly due to the variation in the microstructure of the binder, which in the case of mortars represents only part of the material, but in pastes constitutes $100 \%$ of the material. However, no explanation has yet been put forward for the surprising variation of $\mathrm{D}_{\mathrm{S}}$ with the $\mathrm{B} / \mathrm{Ag}$ ratio.

As far as the mechanical properties are concerned, in mortars with a lime-rich binder, carbonation predominates as the hardening process, so the mechanical strengths increase in parallel with the carbonation process. The setting time in lime mortars with small amounts of cement (mortars with a cement-lime ratio of 1-8) is remarkably shortened: this fact is useful to apply the mortars in the monument.

In the rich-in-cement mortars, the dry curing conditions, in comparison to more suitable conditions for hydration of calcium silicates (HR of $100 \%$ ), could have had some negative influence on the curing process and could explain the increase in strength at the beginning of the curing days and the subsequent drop in strength. In the literature, a decrease in strength has been reported at certain days, followed by a later increase when the curing of cement takes place at temperatures of $35^{\circ} \mathrm{C}$ (in water or steam) [13]. In addition, the volume increase of the $\mathrm{Ca}(\mathrm{OH})_{2}$ as a result of its carbonation might create microcracks that could have an influence on the mechanical properties [23].

Blended mortars with around $40 \%$ of lime, $60 \%$ of cement present compressive strength very similar to that of natural hydraulic lime-based mortars, with a $\mathrm{B} / \mathrm{Ag}$ volume ratio of (1:2) [7]. Moreover, this strength is achieved quickly (7 days). This compressive strength could be large enough to repair mortars [4].

Two opposite factors must be taken into consideration when a mix of a repair mortar is designed: i) the increase in strength when the amount of binder increases; ii) the 
decrease in strength as a result of cracks that can be produced as a consequence of the shrinkage [7].

From the data in Figure 7, it can be stated that mortars with a lime-rich binder, in spite of their lower strengths, are able to absorb a high degree of deformation before breakage, due to their plastic zone. Owing to this fact, these mortars are very interesting materials for restoration work: they can accommodate the movements of ancient buildings $[3,4]$.

Both the Young's modulus of compressive and flexural strength have been evaluated at the $365^{\text {th }}$ curing day (Fig. 8). In both cases, the modulus increases with the increase in the percentage of cement in the binder and with the increase in the $\mathrm{B} / \mathrm{Ag}$ ratio. The difference for Young's modulus between mortars with different B/Ag ratio is smaller for lime-rich mortars.

In the case of cement-rich mortars, their strong rigidity could put the material under strain, which could give rise to cracks, causing the breakage of the material during its service life. Nevertheless, due to their higher flexibility, as well as to the presence of a large plastic zone which allows the absorption of the movements of the wall, lime-rich mortars are materials with a long service life for restoration of Cultural Heritage buildings. In addition, in these mortars the dissolution-precipitation cycles of the calcite allow sealing of cracks by self-repair [31].

\section{Conclusions}

1. The surface fractal dimension has been used as indicator of the complexity of the pore system. The Ds increases proportionally to the percentage of cement in the binder. The variation of Ds with the $\mathrm{B} / \mathrm{Ag}$ ratio is unexpected, showing a minimum for the intermediate $\mathrm{B} / \mathrm{Ag}$ ratio of $1: 3$. 
2. When $0-40 \%$ of cement is added to lime-based mortars, their mechanical strength increases slightly. In cement mortars, the mechanical strength diminishes sharply when a small amount of lime is added (25\% of lime gives rise to a drop in strength of around $50 \%)$.

3. From the results for Young's modulus, it can be stated that the lime-rich mortars present a plastic zone that does not appear in the other blended mortars. Therefore, limerich mortars are able to absorb a high degree of deformation before the breakage. Due to this, these mortars have great potential as materials for restoration work: they can accommodate the movements of ancient buildings.

\section{Acknowledgements}

The present study was supported by the Spanish Ministerio de Ciencia y Tecnología, Plan Nacional de Investigación, Desarrollo e Innovación Tecnológica (I+D+I) program, Project MAT 2000-1347.

\section{References}

[1] A. Moropoulou, A. Bakolas, P. Moundoulas, E. Aggelakopoulou, S. Anagnostopoulou, Strength development and lime reaction in mortars for repairing historic masonries, Cem. Concr. Res., 27 (2005) 289-294.

[2] J. Lanas, J.I. Alvarez, Masonry repair lime-based mortars: Factors affecting the mechanical behaviour, Cem. Concr. Res., 33 (2003) 1867-1876.

[3] M.J. Mosquera, D. Benitez, S.H. Perry, Pore structure in mortars applied on restoration: Effects on properties relevant to decay of granite buildings, Cem. Concr. Res., 32 (2002) 1883-1888. 
[4] E. A.W. Hendry, Masonry walls: material and construction, Constr. Build. Mater., 15 (2001) 323-330.

[5] Y. Sébaïbi, R. M. Dheilly, M. Quéneudec, A study of the viscosity of lime-cement paste: influence of the physico-chemical characteristics of lime, Constr. Build. Mater., 18 (2004) 653-660.

[6] A.H.P. Maurenbrecher, Mortars for repair of traditional masonry, Practice Periodical on Structural Design and Construction, 9 (2004) 62-65.

[7] J. Lanas, J.L. Pérez Bernal, M.A. Bello, J. I. Alvarez Galindo, Mechanical properties of natural hydraulic lime-based mortars, Cem. Concr. Res., 34 (2004) $2191-2201$

[8] P. Manita, T.C. Triantafillou, The effect of aggregate composition on physical and mechanical characteristics of repair mortars, Advances in Architecture, 15 (2003) 781-790.

[9] P.J.P. Gleize, A. Müller, H.R. Roman, Microstructural investigation of a silica fume-cement-lime mortar, Cem, Concr. Comp., 25 (2003) 171-175.

[10] M. Arandigoyen, J.I. Alvarez, Blended pastes of cement and lime: Pore structure and capillary porosity, Appl. Surf. Sci., (Available on www.sciencedirect.com)

[11] M. Arandigoyen, B. Bicer-Simsir, J.I. Alvarez, D.A. Lange, Variation of microstructure with carbonation in lime and blended pastes, Appl. Surf. Sci., (2005) (Available on www.sciencedirect.com)

[12] K. Van Balen, D. Van Gemert, Modelling lime mortar carbonation, Mater. Struct., 27 (1994) 393-398.

[13] F.M. Lea, The chemistry of cement and concrete, Glasgow, Edward Arnold (1970). 
[14] Y.F. Houst, F.H. Wittmann, Influence of porosity and water content on the diffusivity of $\mathrm{CO}_{2}$ through hydrated cement paste, Cem. Concr. Res., 24(6) (1994) $1165-1176$

[15] N.S. Martys, C.F. Ferraris, Capillary transport in mortars and concrete, Cem. Concr. Res., 27 (5) (1997) 747-760.

[16] M.S. Goual, F. de Barquin, M.L. Benmaled, A. Bali, M. Quéneudec, Estimation of the capillary transport coefficient of Clayey Aerated Concrete using a gravimetric technique, Cem. Concr. Res., 30 (2000) 1559-1563.

[17] V. Fernandes, L. Silva, V.M. Ferreira, J.A. Labrincha, Influence of the kneading water content in the behaviour of single-coat mortars, Cem, Concr. Res., 35 (2005) 1900-1908.

[18] UNE-EN 459-1, Building Lime: Part 1. Definition, specification and conformity criteria, 1996.

[19] UNE 80.301:1996 Cementos comunes: Composición especificaciones y criterios.

[20] UNE 83-811-92, Mortars, Test Methods, Fresh Mortars, Determination of consistence, Flow Table, reference Method, 1992.

[21] RILEM, Mater. Struct. 13 (1980) 175-253.

[22] M. Arandigoyen, J.L Pérez Bernal, M.A Bello López, J.I. Alvarez, Lime pastes with different kneading water: pore structure and capillary porosity, Appl. Surf. Sci., (2005) (Available on www.sciencedirect.com)

[23] H.F.W. Taylor, La química de los cementos, (1978) Ed. URMO.

[24] Y. Wang, S. Diamond, A fractal study of the fracture surfaces of cement pastes and mortars using a stereoscopic SEM method, Cem. Concr. Res., 31 (2001) 1385-1392. 
[25] J.L. Pérez Bernal, M.A Bello López, Fractal geometry and mercury porosimetry Comparison and application of proposed models on building stones, Appl. Surf. Sci., 185 (2001) 99-107.

[26] A. Stazi, M. D’Orazio, E.Quagliarini, In-life prediction of hygrometric behaviour of buildings materials: an application of fractal geometry to the determination of adsorption and suction properties Build. Environ 37 (2002) 733-739.

[27] B. Zhang, S Li, Determination of the surface fractal dimension for porous media by mercury porosimetry, Ind. Eng. Chem. Res., 34 (1995) 1383-1386.

[28] P. Pfeifer, M. Obert, in: D. Avnir (Ed.), The Fractal Approach to Heterogeneous Chemistry, Wiley, New York, 1989, p.16.

[29] V. Fernandes, L. Silva, V.M. Ferreira, J.A. Labrincha, Evaluation of mixing and application process parameters of single-coat mortars, Cem. Concr. Res., 35 (2005) 836-841.

[30] K.L. Scrivener, K.M. Nemati, The percolation of pore space in the cement paste/aggregate interfacial zone of concrete, Cem. Concr. Res., 26 (1996) 35-40.

[31] C. Rodríguez-Navarro, E. Sebastián, G. Cultrone, Aging of lime putty: Effects on traditional lime mortar carbonation, J. Am. Cera. Soc, 83 (5) (2000) 3032-3034. 
Table 1. Cement / Lime / Aggregate ratios (by volume) of the mortars elaborated.

\begin{tabular}{|c|c|c|c|c|c|c|c|}
\hline & \multicolumn{7}{|c|}{ Cement / Lime } \\
\hline B / Ag & $\mathbf{0}-\mathbf{1}$ & $\mathbf{1}-\mathbf{4}$ & $\mathbf{1}-\mathbf{2}$ & $\mathbf{1}-\mathbf{1}$ & $\mathbf{2}-\mathbf{1}$ & $\mathbf{4}-\mathbf{1}$ & $\mathbf{1}-\mathbf{0}$ \\
\hline $\mathbf{1}-\mathbf{2}$ & $0-1-2$ & $1-4-10$ & $1-2-6$ & $1-1-4$ & $2-1-6$ & $4-1-10$ & $1-0-2$ \\
\hline $\mathbf{1}-\mathbf{3}$ & $0-1-3$ & $1-4-15$ & $1-2-9$ & $1-1-6$ & $2-1-9$ & $4-1-15$ & $1-0-3$ \\
\hline $\mathbf{1}-\mathbf{4}$ & $0-1-4$ & $1-4-20$ & $1-2-12$ & $1-1-8$ & $2-1-12$ & $4-1-20$ & $1-0-4$ \\
\hline
\end{tabular}

Table 2. Chemical analysis of the main components of the hydrated commercial lime powder $(\text { Ecobat } \AA)^{\mathrm{a}, \mathrm{b}}$, the Portland cement CEM II-A/L 32.5 and the aggregate used.

\begin{tabular}{|c|c|c|c|c|c|c|c|c|}
\hline & $\begin{array}{c}\mathbf{L O I}^{\mathbf{c}} \\
(\mathbf{\%})\end{array}$ & $\begin{array}{c}\mathbf{S i O}_{2} \\
(\mathbf{\%})\end{array}$ & $\begin{array}{c}\mathbf{C a O} \\
(\mathbf{\%})\end{array}$ & $\begin{array}{c}\mathbf{M g O} \\
(\mathbf{\%})\end{array}$ & $\begin{array}{c}\mathbf{R}_{2} \mathbf{O}_{3}{ }^{\mathbf{d}} \\
(\mathbf{\%})\end{array}$ & $\begin{array}{c}\mathbf{S O}_{3} \\
(\mathbf{\%})\end{array}$ & $\begin{array}{c}\mathbf{N a}_{2} \mathbf{O} \\
(\%)\end{array}$ & $\begin{array}{c}\mathbf{K}_{2} \mathbf{O} \\
(\%)\end{array}$ \\
\hline Lime & 25.25 & 1.03 & 68.53 & 3.29 & 0.89 & 1.37 & 0.09 & 0.05 \\
\hline Aggregate & 43.10 & 0.49 & 52.83 & 2.28 & 1.14 & 0.57 & 0.07 & 0.05 \\
\hline
\end{tabular}

${ }^{\text {a }}$ Percentages related to original dry lime.

${ }^{\mathrm{b}}$ The methods specified by the European Standard EN-196 were followed for the chemical analyses.

${ }^{\mathrm{c}}$ Loss of ignition indicates the weight loss due to calcinations at $975-1000^{\circ} \mathrm{C}$

${ }^{\mathrm{d}}$ Percentage of $\mathrm{Fe}$ and $\mathrm{Al}$ oxides together.

Table 3. Porosity of the different mortars.

\begin{tabular}{|c|c|c|c|c|c|c|c|c|}
\hline \multicolumn{2}{|c|}{ Porosity (\%) } & \multicolumn{8}{|c|}{ Cement / Lime } \\
\cline { 3 - 9 } \multicolumn{2}{|c|}{} & $\mathbf{0 - 1}$ & $\mathbf{1 - 8}$ & $\mathbf{1 - 4}$ & $\mathbf{1 - 2}$ & $\mathbf{1 - 1}$ & $\mathbf{2 - 1}$ & $\mathbf{1 - 0}$ \\
\hline \multirow{3}{*}{ B/Ag } & $\mathbf{1 : 2}$ & 23.06 & 22.14 & 22.44 & 22.59 & 22.39 & 21.86 & 20.91 \\
\cline { 2 - 9 } & $\mathbf{1 : 3}$ & 20.87 & 20.57 & 21.41 & 21.37 & 21.62 & 21.45 & 20.62 \\
\cline { 2 - 9 } & $\mathbf{1 : 4}$ & 20.41 & 19.16 & 21.03 & 21.46 & 21.47 & 21.17 & 20.49 \\
\hline
\end{tabular}




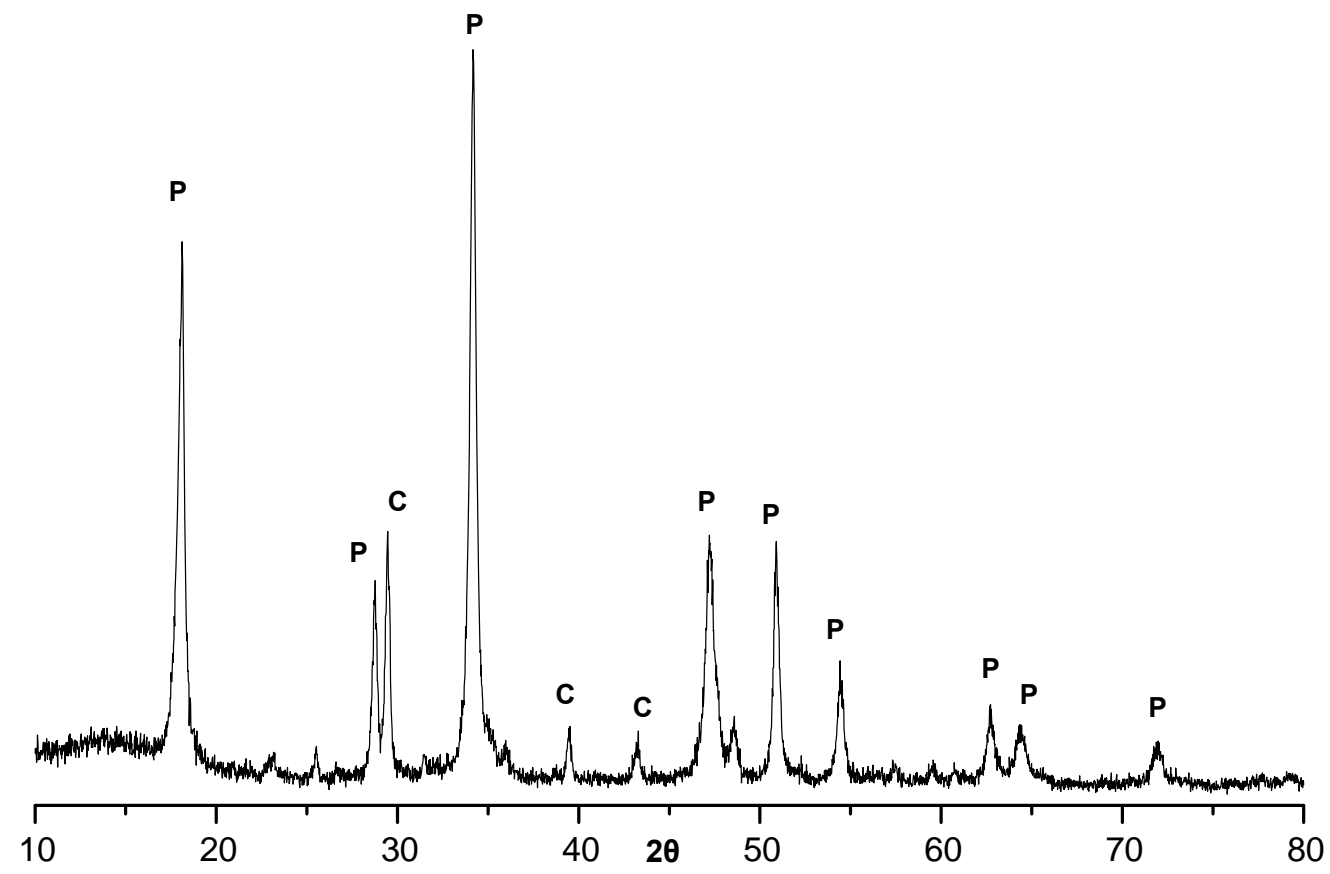

Figure 1. XRD of the lime Ecobat ${ }^{\circledR}$ (C: Calcite (ICDD 05-0586); P: Portlandite (ICDD 44-1481)). 


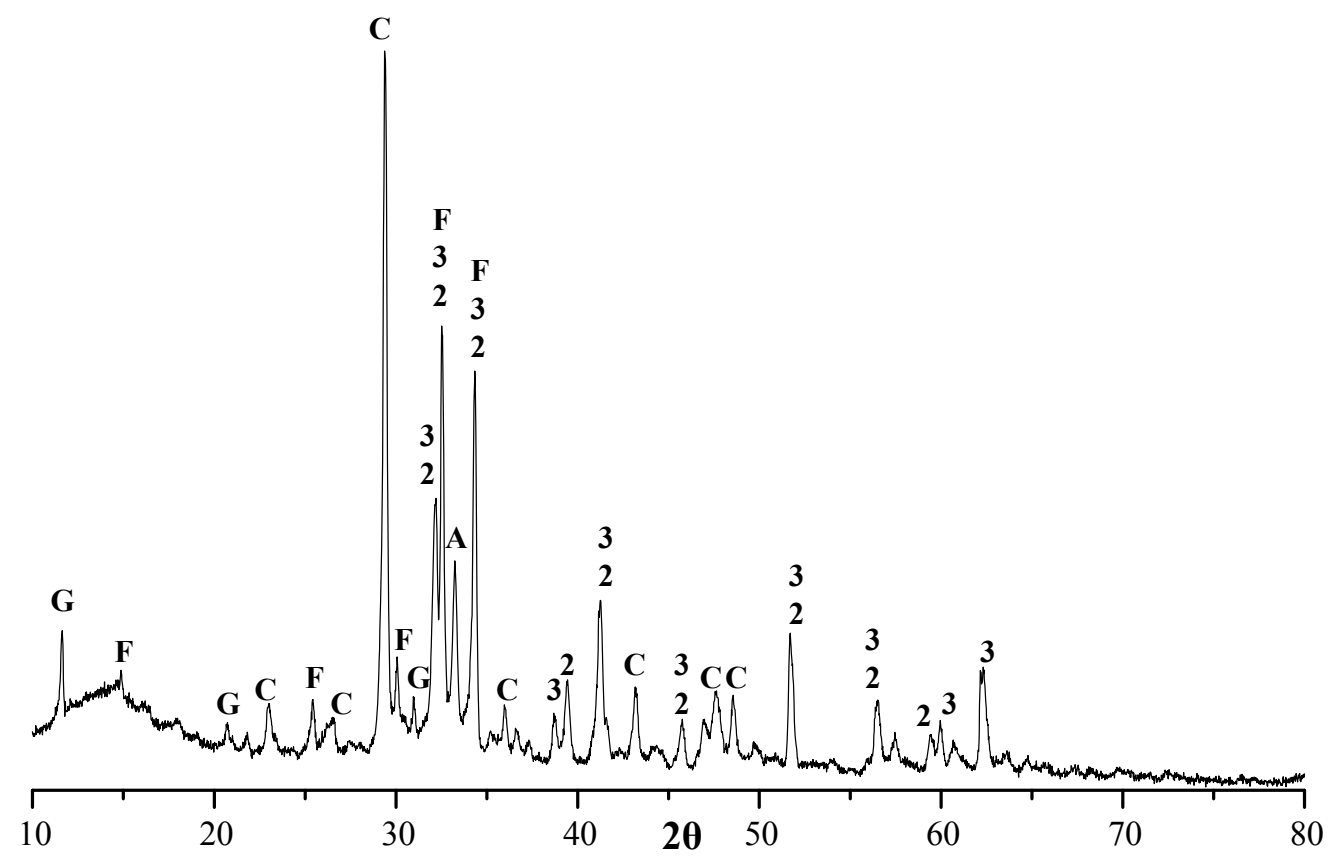

Figure 2. XRD of the cement CEM II-A/L 32.5 (C: Calcite (ICDD 05-0586); 2: Dicalcium silicate (ICDD 02-0843); 3: Tricalcium silicate (ICDD 02-0849); G: Calcium sulphate hydrated (ICDD 01-0385); A: Calcium aluminate (ICDD 38-1429)), F: Aluminoferrite (ICDD 85-1092).

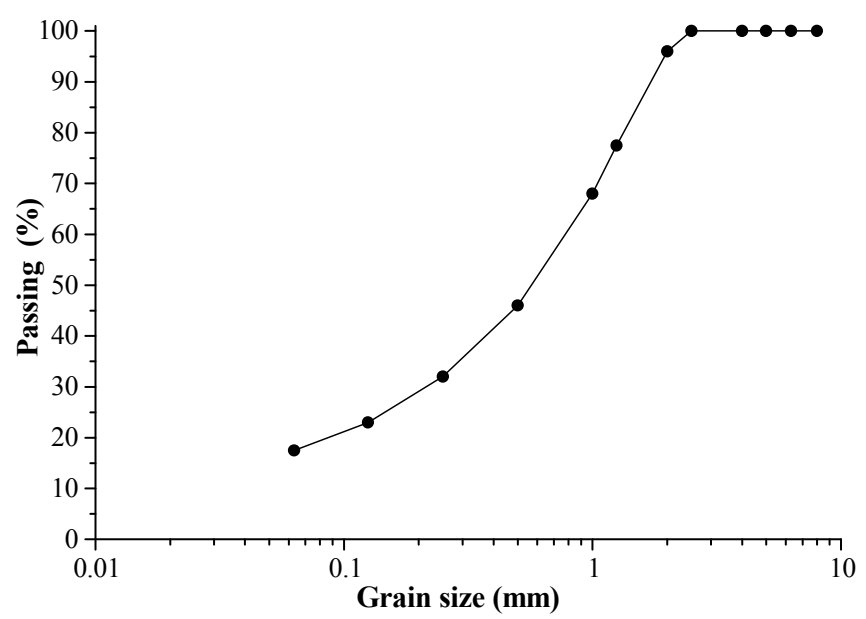

Figure 3. Grain size distribution of the aggregate. 

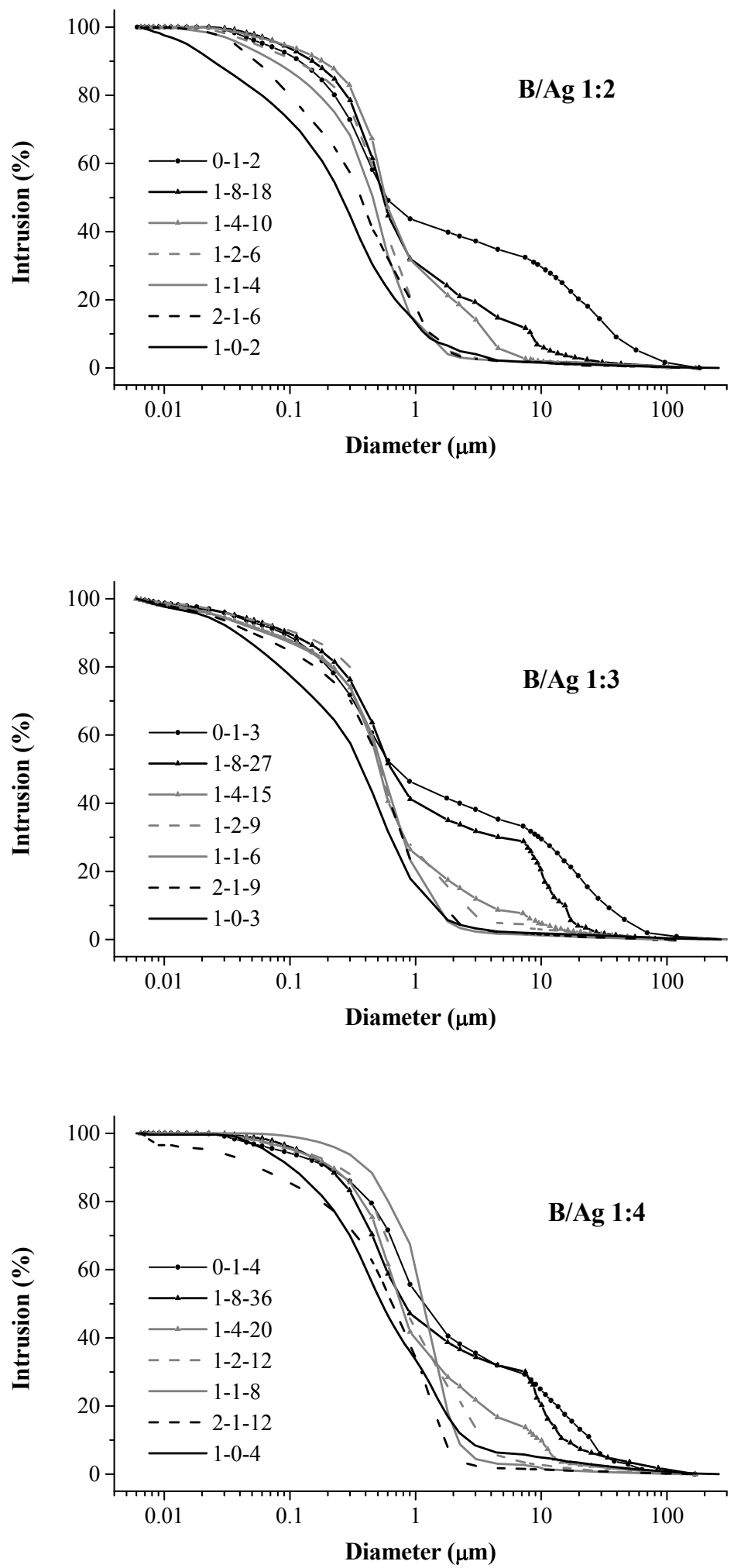

Figure 4. Cumulative pore size distributions (\%) of the mortars with a $\mathrm{B} / \mathrm{Ag}$ ratio of: $1: 2,1: 3$ and $1: 4$ 


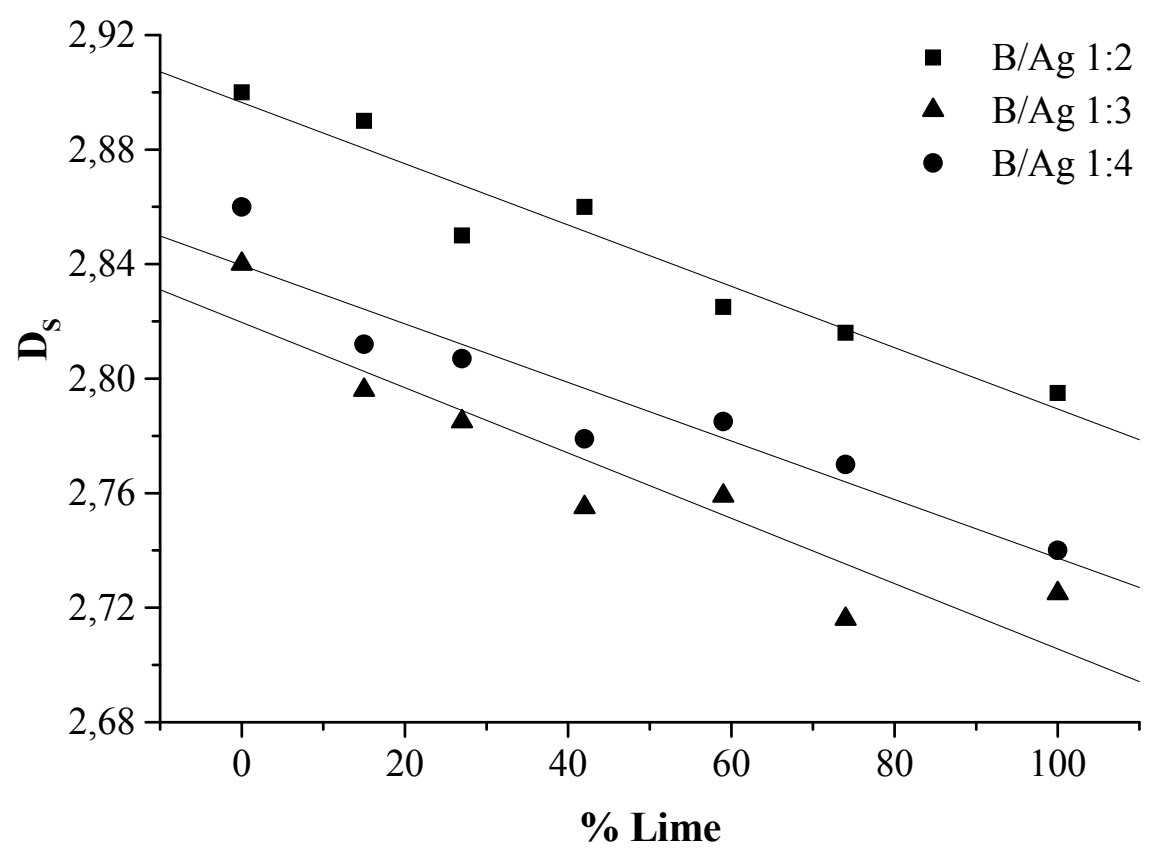

Figure 5. Surface fractal dimension for the different mortars composition 

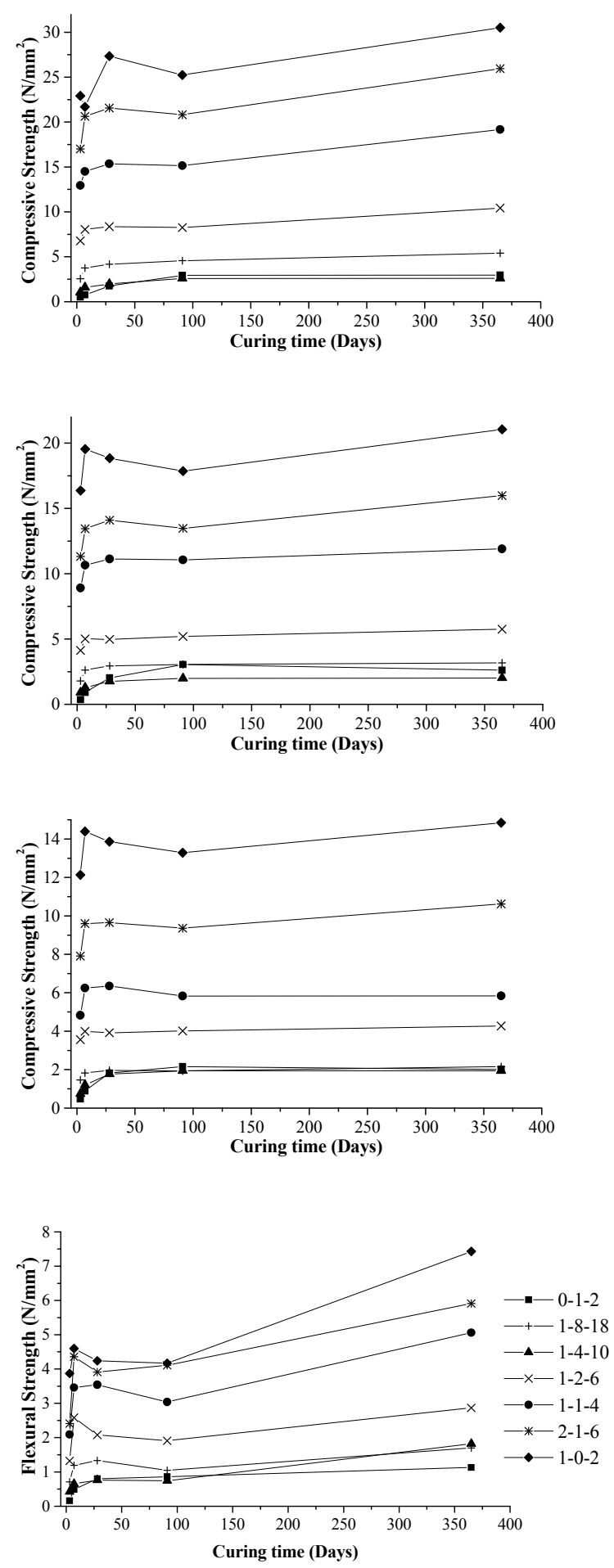

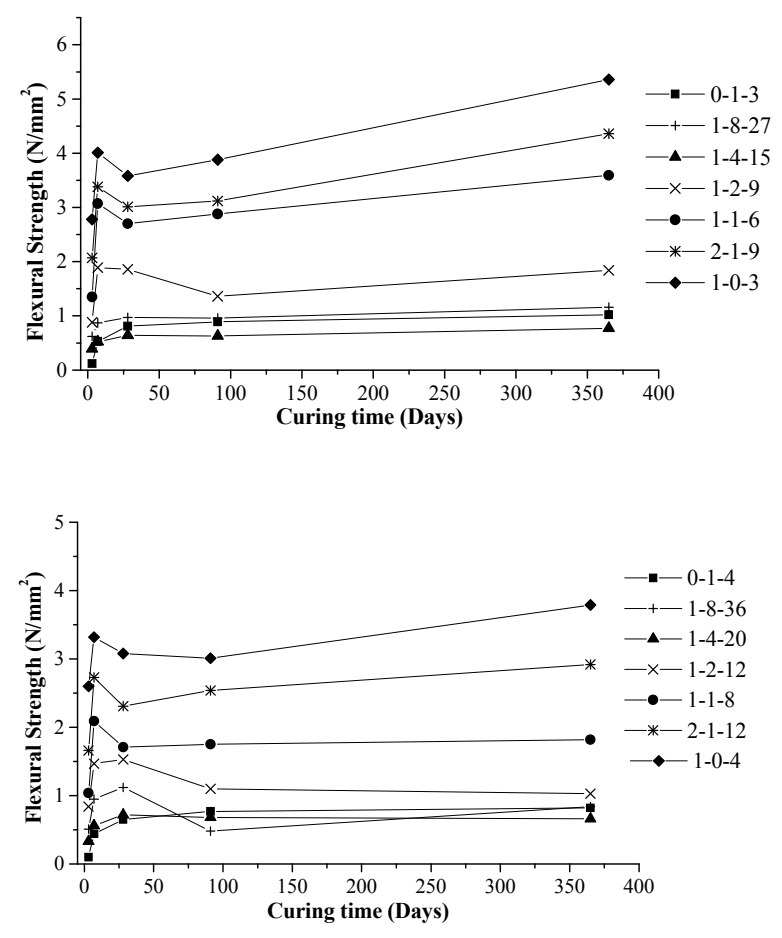

Figure 6. Compressive and flexural strength versus the curing time.

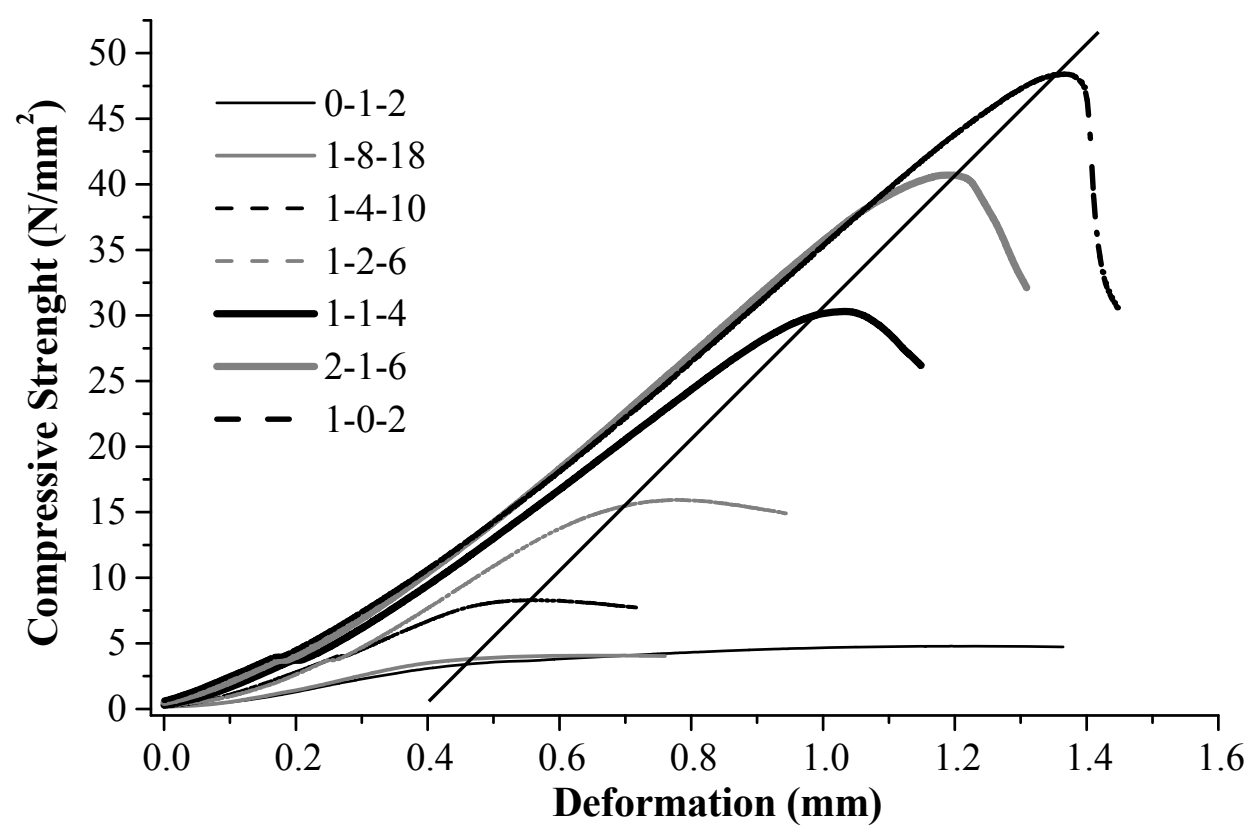

Figure 7. Compressive strength $\left(\mathrm{N} / \mathrm{mm}^{2}\right)$ vs. deformation (mm). 

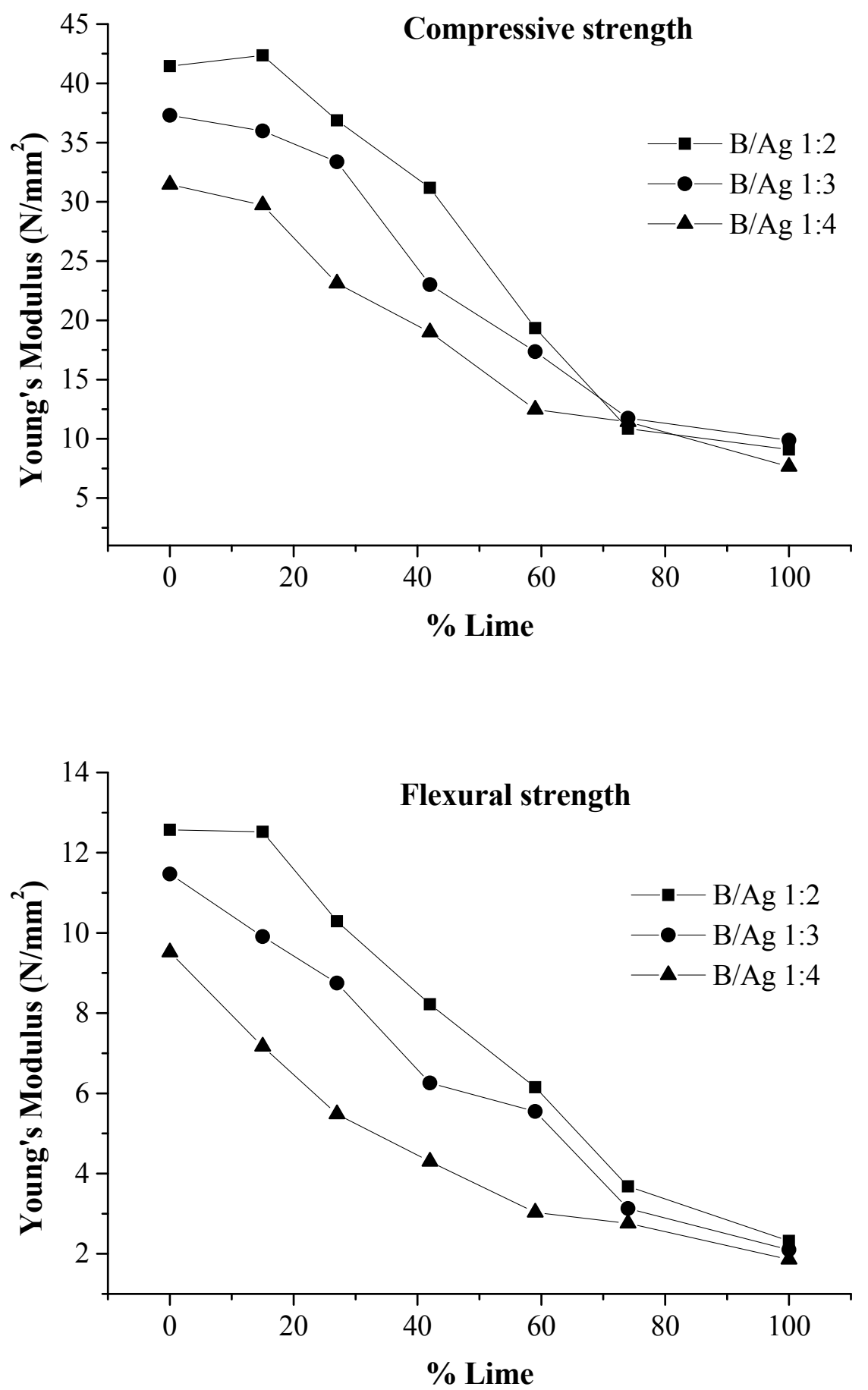

Figure 8. Young's modulus $\left(\mathrm{N} / \mathrm{mm}^{2}\right)$ at 365 days of flexural strength and compressive strength. 